\title{
Analysis of miR-221 and p27 expression in human gliomas
}

\author{
XIAOMING LU $^{1 *}$, PENG ZHAO $^{1 *}$, CHUNZHI ZHANG $^{2 *}$, ZHEN FU $^{1}$, YUNXIANG CHEN $^{1}$, \\ AILING LU ${ }^{1}$, NIN LIU ${ }^{1}$, YONGPING YOU ${ }^{1}$, PEIYU PU ${ }^{2}$ and CHUNSHENG KANG ${ }^{2}$ \\ ${ }^{1}$ Department of Neurosurgery, The First Affiliated Hospital of Nanjing Medical University, Nanjing 210029; \\ ${ }^{2}$ Department of Neurosurgery, Tianjin Medical University General Hospital, and Laboratory of \\ Neuro-oncology, Tianjin Neurological Institute, Tianjin 300052, P.R. China
}

Received October 29, 2008; Accepted April 24, 2009

DOI: $10.3892 / \mathrm{mmr}+00000152$

\begin{abstract}
MicroRNAs (miRNAs) are short ( 22-nt) noncoding RNA molecules implicated in both development and disease that act by repressing translation or by inducing the cleavage of target RNA transcripts. Emerging evidence suggests that the altered regulation of miRNA may be involved in the pathogenesis of cancer. Here, we investigated the expression of the miRNA gene miR-221 by real-time PCR in human glioma tissues of varying grades of malignancy. The expression level of miR-221 was found to increase with glioma malignancy, whereas protein levels of a putative target, the cell cycle inhibitor and tumor suppressor gene p27 Kip1 decreased. Using a luciferase reporter assay, we further confirmed the translational repression activity of miR-221 on p27 by identifying the target recognition element within the 3'UTR of p27. Our results suggest that miR-221 is a regulator of the tumor suppressor gene 27 , and that its increased expression in advanced gliomas might contribute to glioma cell proliferation by a mechanism involving the repression of $\mathrm{p} 27$.
\end{abstract}

\section{Introduction}

Gliomas are the most common form of primary intracranial tumors, constituting $40-60 \%$ of all brain tumors. Although gliomas vary widely in their malignancy, patients suffering from the most severe forms of malignant glioma have a life

Correspondence to: Dr Yongping You,Department of Neurosurgery, The First Affiliated Hospital of Nanjing Medical University, Nanjing 210029, P.R. China

E-mail: yyp19@njmu.edu.cn

Dr Chunsheng Kang, Department of Neurosurgery, Tianjin Medical University General Hospital, and Laboratory of Neuro-oncology, Tianjin Neurological Institute, Tianjin 300052, P.R. China

E-mail: kang97061@gmail.com

${ }^{*}$ Contributed equally

Key words: microRNA, glioma, miR-221, quantitative real-time PCR, p27 expectancy of $\sim 9-12$ months following diagnosis. Over the past several years, molecular genetic research has uncovered a large number of genes contributing to human cancer. In particular, a number of genetic markers associated with glioma malignancy have been found and may prove to be useful diagnostic tools and therapeutic targets (1). Despite the large number of glioma-associated genes identified to date, many may have been overlooked, as most efforts in genomics have focused exclusively on identifying annotated protein-coding genes.

It was recently discovered that an unexpectedly large fraction of the genome has been transcribed (2). Many of the unexpected loci harbor non-coding RNAs (ncRNAs) that do not contain an open reading frame or code for protein. The best characterized group of ncRNAs are microRNAs (miRNAs), 22-nt non-coding RNAs that post-transcriptionally regulate gene expression through the RNA interference (RNAi) pathway (3). miRNAs are generated as a primary transcript (pri-miRNA) by RNA polymerase II, and are then sequentially processed by the ribonucleases Drosha and Dicer to yield mature miRNA. The mature miRNAs are loaded into the RNAi effector complex RNA-induced silencing complex, where they bind to mRNAs $(4,5)$. In general, miRNAs bind to partially matching sequences in the 3'UTRs of target mRNAs and mediate translational repression (6), or target mRNAs for degradation when matching is more stringent $(7,8)$.

The aberrant expression of miRNAs in cancer has been well documented (12). miRNAs may function as tumor suppressors or as oncogenes by targeting oncogenes or tumor suppressor genes, respectively. A number of studies have found miR-221 miRNA to be overexpressed in tumors, indicating that upregulation of miR-221 may be an early event in carcinogenesis (14-16). One of the putative targets of miR-221 is p27 Kip1 mRNA (17). The p27 gene is a member of the Cip/Kip family of cyclin-dependent kinase (CDK) inhibitors, and serves to arrest cell cycle progression (18). By binding to CDK2 and cyclin E complexes, p27 prevents cell cycle progression from the G1 to S phase. p27 also acts as a tumor suppressor, and its expression is often disrupted in human cancers. Studies in mice have shown that the loss of p27 increases tumor incidence and growth rate in specific genetic backgrounds or when mice are challenged with carcinogens (19). Decreased p27 levels have been correlated with tumor aggressiveness and poor patient survival (20-25). 
In the present study, we examined the expression of miR-221 and p27 in 29 glioma samples, and found that the expression of miR-221 increased in conjunction with the grade of the glioma, while the expression of $\mathrm{p} 27$ decreased. The putative target recognition site of miR-221 in the 3'UTR of p27 was confirmed, and the robust translational repression activity of miR-221 on this element was demonstrated using a luciferase expression assay. Collectively, the data presented herein provide evidence that increased expression of miR-221 in gliomas may affect the aggressiveness of tumors by increasing the proliferative potential of glioma cells via p27 repression.

\section{Materials and methods}

Patients and samples. Primary tumor samples from 29 glioma patients were obtained during surgical resection of the lesion. Samples for miR-221 and p27 expression analysis were taken from biopsy material obtained using standard diagnostic procedures. Immediately after surgery, samples were snap-frozen and stored in liquid nitrogen until RNA extraction. Histological diagnosis and grading of tumors were carried out in compliance with WHO criteria (World Health Organization, 2000). A total of 13 tumors were classified as low-grade gliomas, 8 as anaplastic astrocytomas, and the remaining 8 as glioblastoma multiformes (GBMs). Details regarding tumor type and grade are listed in Table I. Of the 29 glioma patients, 16 were male and 13 were female. The mean age at diagnosis was $30.3 \pm 10.6$ years for patients with low-grade tumors, $44.9 \pm 7.3$ years for patients with anaplastic astrocytomas and $53.9 \pm 12.9$ years for patients with GBMs.

Quantitative real-time $R T-P C R$ of $m i R-221$. The mirVana qRT-PCR miRNA Detection Kit (P/N: 1556, Ambion) was used to detect the presence of miR-221, along with 5S rRNA to normalize for RNA content among different samples (26). Real-time PCR was performed using standard protocols on a Bio-Rad Chromo4 Detection System using gene-specific 'reverse' stem-loop primers for miR-221 and 5S rRNA purchased from Ambion (P/N: 30115 and 30302) and a universal primer common to all cDNAs. Briefly, total RNA was extracted from tumor samples using the mirVana ${ }^{\mathrm{TM}}$ PARIS $^{\mathrm{TM}}$ Isolation Kit (P/N: 1558, Ambion) according to the manufacturer's protocol. cDNAs were then transcribed from RNA at $37^{\circ} \mathrm{C}$ for $30 \mathrm{~min}$, followed by $10 \mathrm{~min}$ at $95^{\circ} \mathrm{C}$ to inactivate the reverse transcriptase. The chimeric cDNA was amplified over 40 cycles at $95^{\circ} \mathrm{C}$ for $15 \mathrm{sec}$ and $60^{\circ} \mathrm{C}$ for $30 \mathrm{sec}$ and monitored with SYBR Green (Invitrogen) fluorescence. To control the specificity of the amplifications, the melting temperature of the PCR product was determined using Opticon Monitor-3 melting curve analysis, and the relative amount of miRNA was normalized to the amount of $5 \mathrm{~S}$ rRNA using the equation $2^{-\Delta \mathrm{C}_{\mathrm{T}}}$, where $\Delta \mathrm{C}_{\mathrm{T}}=$ $\left[\mathrm{C}_{\mathrm{T}(\mathrm{miR}-221)}-\mathrm{C}_{\mathrm{T}(5 \mathrm{~S} R N A)}\right]$ (27). Relative gene expression was multiplied by $10^{4}$ to simplify the presentation of the data. PCRs were performed in triplicate, and included no template controls for each gene. Analysis of the results was conducted in a blinded manner on randomized data.

Analysis of p27 expression by Western blot analysis. Total proteins were extracted from tumor samples using the mirVana PARIS Isolation Kit according to the manufacturer's protocol.
Table I. Tumor type and grade.

\begin{tabular}{lcc}
\hline Type of glioma & WHO grade & No. of cases \\
\hline Low-grade gliomas & & 13 \\
Pilocytic astrocytoma & I & 3 \\
Diffuse astrocytoma & II & 3 \\
Oligoastrocytoma & II & 2 \\
Oligodendroglioma & II & 5 \\
Anaplastic astrocytomas & & 8 \\
Anaplastic astrocytoma & III & 3 \\
Anaplastic oligoastrocytoma & III & 3 \\
Anaplastic oligodendroglioma & III & 2 \\
Glioblastoma multiforme & IV & 8 \\
\hline
\end{tabular}

Protein concentration was measured using the Lowery protein concentration assay, and equal amounts of protein were run on a $12 \%$ SDS-PAGE electrophoresis gel and transferred to a PVDF membrane. The membrane was blocked with $5 \%$ BSA in PBST (PBS, pH 7.5, and s0.1\% Tween-20) and then incubated in 1:500 goat anti-p27 (Santa Cruz Biotechnology) overnight at $4^{\circ} \mathrm{C}$. The membrane was washed with PBST and incubated in 1:2000 peroxidase-conjugated rabbit anti-goat secondary antibody (Santa Cruz Biotechnology) for $1 \mathrm{~h}$ after washing. The signal was then developed using a chemiluminescence detection system (Cell Signaling) according to the manufacturer's recommendations. Western blot films were digitized, and the net intensities of bands were quantified using Quantity One software (Bio-Rad). After being developed, the membrane was stripped and reprobed with an antibody against GAPDH to confirm equal sample loading.

Cell culture and transfections. U251 glioblastoma cells were obtained from the Institute of Biochemistry and Cell Biology, Chinese Academy of Science, Shanghai, and maintained in DMEM supplemented with $10 \%$ fetal bovine serum, $100 \mathrm{U} / \mathrm{ml}$ penicillin and $100 \mu \mathrm{g} / \mathrm{ml}$ streptomycin at $37^{\circ} \mathrm{C}$ in an atmosphere of $5 \% \mathrm{CO}_{2}$. A pGL-3 plasmid containing the 3'UTR of human p27 and the double-mutant 3'UTR of human p27 were kind gifts from Dr Reuven Agami (The Netherlands Cancer Institute). Construction of pGL-p27-3'UTR and pGL-p273'UT-DM were as described previously (28). Briefly, the 3'UTR of p27 was synthesized from genomic DNA using forward TTC TTAAACAGCTCGAATTAAGAATATGTTTCC and reverse TTTTCTTTATTGATTACTTAATGTG primers. The p27 Sen-Luc was prepared by digesting the 3'UTR of p27 and subcloning it into pGL3 (Promega) downstream of the luciferase gene. The pGL3-p27-3'UTR-DM (double mutant) was created by a site mutation method (28).

U251 cells were plated in 24-well microplates (Corning, USA) at a density of $1.0 \times 10^{5}$ cells per well. The luciferase assay was performed as described previously (28) with little modification. 2'-O-methyl (2'-OMe)-oligonucleotides were chemically synthesized by GenePharma Co., Ltd. (Shanghai, China). 2'-O-methyl oligos were composed entirely of 2'-O-methyl bases and consisted of the following sequences, antisense to 
the mature form of human miR-221: 2'OMe-miR-221 5'-GUCAACAUCAGUCUGAUAAGCUA-3'. Cells were divided into three groups, including control 2'OMe-miR-221 + pGL3p27-3'UTR and 2'OMe-miR-221 + pGL3-p27-3'UTR-DM. Luciferase activity was measured $72 \mathrm{~h}$ after transfection using the Dual-luciferase reporter assay system (Promega).

Statistical analysis. All quantifications were expressed as arbitrary units and presented as the mean \pm SD. For each experiment, all assays were performed at least in triplicate. Data were analyzed with Stata 7.0. The relative amounts of miR-221 and p27 among the three test groups were compared using the Kruskal-Wallis test followed by a post-hoc Bonferroni adjustment. A statistical significance level was assigned to values of $\mathrm{P}_{\mathrm{adj}} \leq 0.05$. Other analyses of statistical links between biological and clinical parameters were performed using standard tests.

\section{Results}

miR-221 and p27 expression in gliomas. On the basis of malignancy and according to WHO criteria, we divided the 29 glioma samples into three groups: low grade, anaplastic and GBM. The concentration of miR-221 miRNA and the protein levels of p27 tumor suppressor gene were then measured.

miR-221 miRNA levels were determined using real-time RT-PCR. Taking the average for each tumor grade group, we found a significant positive correlation between miR-221 miRNA levels and tumor severity (Kruskal-Wallis test, $\left.\chi^{2}=19.960, \mathrm{P}=0.000\right)$. As shown in Fig. $1 \mathrm{~A}$, the relative amount of miR-221 was significantly different in the low-grade gliomas compared to the GBMs $\left(\chi^{2}=16.545, \mathrm{P}_{\mathrm{adj}}=0.000\right)$ and in the anaplastic astrocytomas compared to the GBMs $\left(\chi^{2}=9.414\right.$, $\left.P_{\text {adj }}=0.006\right)$. Although the miR-221 level was on average higher in the anaplastic astrocytomas than in the low-grade gliomas, this difference was not significant $\left(\chi^{2}=3.989, \mathrm{P}_{\mathrm{adj}}=0.137\right)$.

Conversely, the relative protein levels of p27 measured by quantified Western blot analysis were inversely related to tumor severity, with a significant difference between the groups $\left(\chi^{2}=21.278, P=0.000\right)$. The average concentration of $\mathrm{p} 27$ was significantly higher in the low-grade gliomas compared to the GBMs $\left(\chi^{2}=14.275, \mathrm{P}_{\mathrm{adj}}=0.000\right)$, as well as in the anaplastic astrocytomas compared to the GBMs $\left(\chi^{2}=9.414, \mathrm{P}_{\mathrm{adj}}=0.006\right)$. The difference in p27 concentration between the low-grade gliomas and the anaplastic astrocytomas was also significant $\left(\chi^{2}=9.698, \mathrm{P}_{\mathrm{adj}}=0.006\right)$ (Fig. 1B and C). A plot of the relative concentrations of $\mathrm{p} 27$ protein against miR-221 miRNA shows an exponential inverse relationship (p27=0.2558x0.9143 ${ }^{\mathrm{miR}-221}$; Fig. 1D). miR-221 and p27 expression were neither age- nor gender-related, as assessed by the Spearman rank test and Kruskal-Wallis test, respectively.

Detection of miR-221 target mRNA by luciferase assay. To further detect whether the 3 'UTR of p27 ${ }^{\mathrm{kip} 1}$ has an miR-221specific binding sequence, we transfected the three types of cells with p3UTR-p27, p3UTRmut-p27 and control plasmid. As expected, anti-miR-221 significantly enhanced luciferase activity.

To determine whether p27 is repressed by miR-221 binding, we used pGL-p27-3'UTR and pGL-p27-3'UT-DM (see Materials and methods). The U251 glioblastoma cells
A

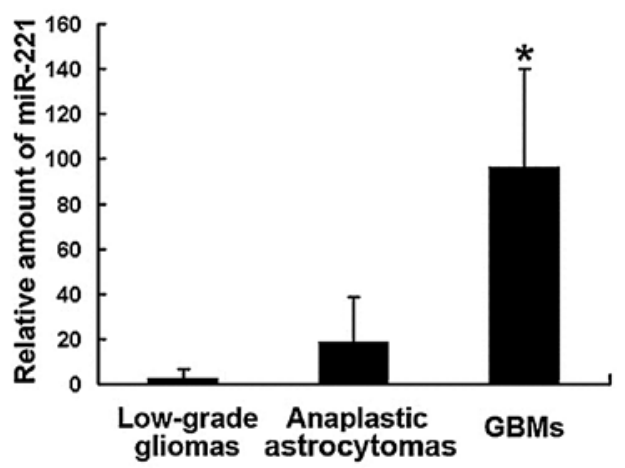

B

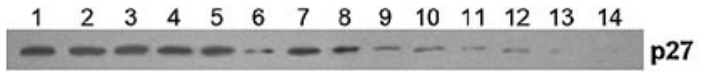

$\mathbf{C}$

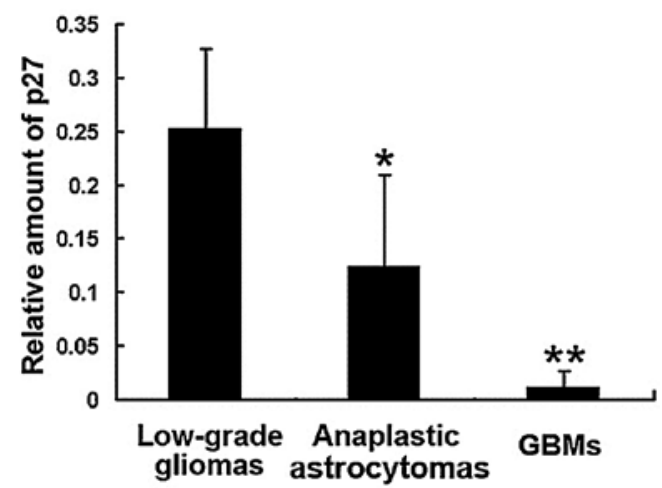

D

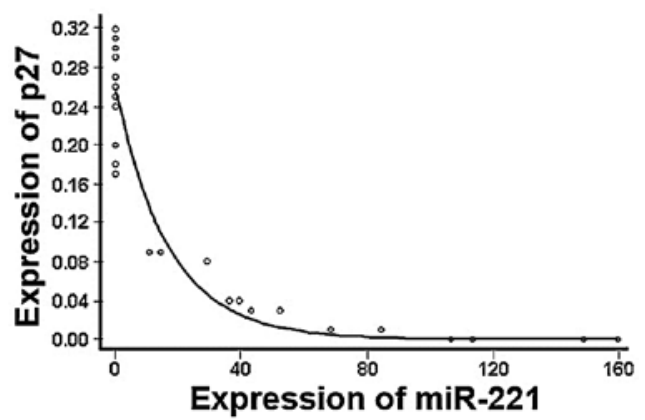

Figure 1. (A) Normalized miR-221 miRNA quantities in gliomas averaged across samples of the same grade. ${ }^{*} \mathrm{P}<0.05$ when compared with low-grade gliomas and anaplastic astrocytomas. (B) Detection of p27 expression in glioma samples by Western blot analysis. Lanes 1-5, low-grade gliomas; 6-10, anaplastic astrocytomas; 11-14, GBMs. (C) Quantification of the average relative concentrations of $\mathrm{p} 27$ protein in the three classes of gliomas. ${ }^{*} \mathrm{P}<0.05$ when compared with low-grade gliomas; ${ }^{* *} \mathrm{P}<0.05$ when compared with low-grade gliomas and anaplastic astrocytomas. (D) Plot of p27 protein concentrations against miR-221 miRNA concentrations in 29 glioma samples. p27 expression decreased exponentially relative to increases in miR-221 along the $\mathrm{p} 27=0.2558 \times 0.9143^{\mathrm{miR}-221}$ trend line.

were transfected by 2'OMe-miR-221 + pGL3-p27-3'UTR and by 2'OMe-miR-221 + pGL3-p27-3'UTR-DM, respectively. We demonstrated that anti-miR-221 as well as anti-miR-222 significantly enhanced luciferase activity (p<0.05; Fig. 2). 


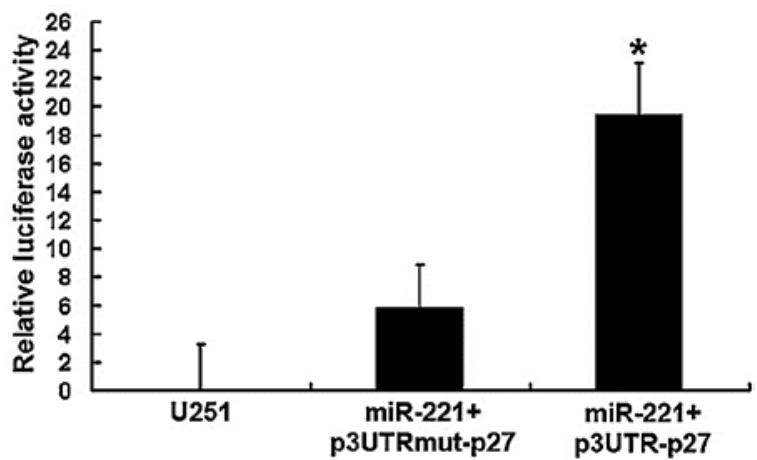

Figure 2. miR-221 directly interacts with p27 3'UTR. The luciferase activity of the control and of p3UTRmut-p27 was significantly less than that of p3UTR-p27 following transfection into miR-221-expressing U251 cells. ${ }^{*} \mathrm{P}<0.05$ when compared with p3UTR-p27.

\section{Discussion}

MicroRNAs (miRNAs) are a class of naturally occurring small non-coding RNAs that regulate gene expression by targeting mRNAs for translational repression or cleavage $(29,30)$. In this study, we measured the expression level of mature miR-221 in tumor specimens from 29 patients with gliomas using a recently introduced technique for quantifying miRNA content in tissue samples by stem-loop RT-PCR (26). We found a progressive increase in miR-221 expression associated with increasing severity of glioma malignancy. The association was particularly strong when comparing GBMs to non-GBMs. These findings indicate that increased miR-221 expression is closely correlated to the pathological grade of gliomas and may be a useful indicator of enhanced glioma malignancy. Using a luciferase assay, we provided evidence that miR-221 targets the 3'UTR of the tumor suppressor gene p27 and represses its translation. This repression may account for the great reduction in p27 observed in advanced malignant gliomas. Collectively, these findings suggest that miR-221 levels may affect the aggressiveness of gliomas, and that this effect is likely to be mediated, at least in part, by the suppression of p27 translation.

Our understanding of the function of miRNA in mammals suggests that these genes play important roles in fate determination and the maintenance of lineage during development. Most miRNA genes are not expressed in embryonic stem cells, but are induced during development. For example, the expression of mammalian let-7 is low in embryonic stem cells and increases during development, reaching a maximum in differentiated adult tissues $(31,32)$. Some miRNAs are expressed in tissue-specific patterns and function to promote differentiation in specific lineages, whereas others are expressed more broadly and function to suppress cell division and to drive terminal differentiation. Lu et al (33) analyzed the expression of 217 mammalian miRNAs in 334 samples, including multiple human cancers, and found that tumors display an expression profile similar to the tissues from which they are derived, while the absolute expression level of many miRNAs is significantly reduced. These results provide compelling evidence that the aberrant suppression of miRNAs might be a necessary step in the oncogenic loss of differentiation.
Although most miRNA genes display reduced expression in cancer, there are notable exceptions. The best characterized example is the mir-17-92 cluster, primary and mature miRNAs that are up-regulated in B-cell lymphomas and strongly accelerate lymphomagenesis (34). miR-221 is clustered on chromosome X11.3 near the closely-related miR-222 (35), and is predicted to have at least 130 targets (15). Of these, Kit is the best established. It was found that miR-221 interacts with the 3'UTR of Kit mRNA, resulting in a dramatic loss of Kit transcripts and proteins. During the exponential growth phase of erythropoietic lineages, the expression of miR-221 is low. Kit protein production is therefore de-repressed, facilitating the expansion of early erythroblasts. Overexpression of miR-221 inhibits normal erythropoiesis and erythroleukemic cell growth (35), and hinders the ability of endothelial cells to form new capillaries (36).

Little is known regarding the function of miR-221 in tumors. However, studies have repeatedly confirmed its up-regulation in various malignancies. Ciafre et al (14) used microarray data to compare the global expression levels of 245 miRNAs in glioblastoma tissue with normal brain tissue, and found that the expression of miR-221 was strongly up-regulated in glioblastoma cells. The study also identified nine overexpressed miRNAs, including the miR-221/222 cluster. Furthermore, miR-221 was confirmed to be overexpressed in all 10 cell lines. Thus, a molecular signature of glioblastoma cells is miR-221 overexpression in glioblastoma tissues and cell lines. Similar results were demonstrated by $\mathrm{He}$ et al (15) and Pallante et al (16), who found that miR-221 expression was up-regulated 3 - to 12-fold in papillary thyroid carcinomas (PTC) compared to normal thyroid tissues from individuals without clinical thyroid disease. Furthermore, elevated expression of miR-221 in normal thyroid tissue adjacent to tumors was proposed to be an early event in carcinogenesis. The blockade of miR-221 function and the overexpression of miR-221 in human PTCderived cell lines also suggest that miR-221 plays a critical role in thyroid carcinogenesis. Collectively, the data strongly suggest that miR-221 is an important factor in carcinogenesis and should be regarded as an OncomiR.

Although p27 is characterized as a tumor suppressor gene, inactivating point mutations with loss of heterozygosity are rarely observed in human cancers. Therefore, the low level of p27 protein observed in many types of aggressive cancer is not likely to be due to mutations at the locus (20). The abundance of $\mathrm{p} 27$ protein is largely controlled through a variety of posttranscriptional regulatory mechanisms (37-39), among which are sequestration by cyclin D/CDK4 complexes, accelerated protein degradation and cytoplasmic retention (18). In certain types of cancer, such as colorectal cancer, overexpression of Skp2 and Cks1, two specific p27 ubiquitin ligase subunits, is strongly associated with low p27 expression and tumor aggressivity (40). However, several studies have indicated that the genes controlling the stability of p27 protein might not always account for its decreased expression in cancer. Instead, p27 may be regulated at the level of translation (41-43).

A recent study revealed that miR-221-expressing HeLa cells had decreased p27 protein levels, and that the half-life of p27 was comparable to that of control cells. Moreover, single miR-221 antagomiR did not affect cellular growth in U87 glioblastoma cells in vitro (28). This indicates a functional overlap 
between miR-221 and miR-222 in controlling proliferation. Noting this, we further demonstrated that the use of adenovirusmediated antisense RNA to co-suppress the expression of miR-221/222 directly resulted in p27 ${ }^{\mathrm{Kip} 1}$ up-regulation in epithelial cancer cell lines, including human U251, SGC7901 and MCF-7 cells. This resulted in the suppression of their growth potential by the induction of a G1 to S shift in the cell cycle (unpublished data). miR-221 and miR-222 knockdown by antisense 2'-OME-oligonucleotides consistently increases $\mathrm{p}^{27 \mathrm{Kipl}}$ in mice subcutaneously transfected with U251 cells, and strongly reduces tumor growth in vivo by up-regulating $\mathrm{p} 27^{\mathrm{Kip} 1}$.

In the present study, we showed that miR-221 targets sequences within the $3^{\prime} \mathrm{UTR}$ of p27 and is capable of arresting the translation of luciferase from a luciferase::p27-3'UTR gene fusion in transfected U251 glioblastoma cells. This in vitro evidence, in conjunction with our finding that p27 protein levels decrease in concert with increased miR-221 expression in human gliomas, supports the conclusion that progressive increases in miR-221 expression lead to the increased translational repression of $\mathrm{p} 27$, thus increasing the malignancy of gliomas.

\section{Acknowledgements}

This work was supported by The National Natural Science Foundation (NNSF no. 30672165 and 30772231), the Jiangsu Province Medical Major Talent Program (RC2007061) and The Program for New Century Excellent Talents in University (NCET-07-0615). We sincerely thank Dr Pengcheng Xun for assistance with data analysis. We apologize to those whose work was not cited due to space limitations.

\section{References}

1. Futreal PA, Coin L, Marshall M, Down T, Hubbard T, Wooster R, Rahman N and Stratton MR: A census of human cancer genes. Nat Rev Cancer 4: 177-183, 2004.

2. Cheng J, Kapranov P, Drenkow J, Dike S, Brubaker S, Patel S, Long J, Stern D, Tammana H, Helt G, Sementchenko V, Piccolboni A, Bekiranov S, Bailey DK, Ganesh M, Ghosh S, Bell I, Gerhard DS and Gingeras TR: Transcriptional maps of 10 human chromosomes at 5-nucleotide resolution. Science 308: 1149-1154, 2005

3. Kim VN: MicroRNA biogenesis: coordinated cropping and dicing. Nat Rev Mol Cell Biol 6: 376-385, 2005.

4. Lee Y, Ahn C, Han J, Choi H, Kim J, Yim J, Lee J, Provost P, Radmark O, Kim S and Kim VN: The nuclear RNase III Drosha initiates microRNA processing. Nature 425: 415-419, 2003.

5. Yi R, Qin Y, Macara IG and Cullen BR: Exportin-5 mediates the nuclear export of pre-microRNAs and short hairpin RNAs. Genes Dev 17: 3011-3016, 2003.

6. Bartel DP: MicroRNAs: genomics, biogenesis, mechanism, and function. Cell 116: 281-297, 2004.

7. Ambros V: The functions of animal microRNAs. Nature 431: 350-355, 2004.

8. Yekta S, Shih IH and Bartel DP: MicroRNA-directed cleavage of HOXB8 mRNA. Science 304: 594-596, 2004.

9. Bentwich I, Avniel A, Karov Y, Aharonov R, Gilad S, Barad O, Barzilai A, Einat P, Einav U, Meiri E, Sharon E, Spector Y and Bentwich Z: Identification of hundreds of conserved and nonconserved human microRNAs. Nat Genet 37: 766-770, 2005.

10. Berezikov E, Guryev V, van de Belt J, Wienholds E, Plasterk RH and Cuppen E: Phylogenetic shadowing and computational identification of human microRNA genes. Cell 120: 21-24, 2005.

11. Lewis BP, Burge CB and Bartel DP: Conserved seed pairing, often flanked by adenosines, indicates that thousands of human genes are microRNA targets. Cell 120: 15-20, 2005.

12. Croce $\mathrm{CM}$ and Calin GA: miRNAs, cancer, and stem cell division. Cell 122: 6-7, 2005.
13. Chen CZ, Li L, Lodish HF and Bartel DP: MicroRNAs modulate hematopoietic lineage differentiation. Science 303: 83-86, 2004.

14. Ciafre SA, Galardi S, Mangiola A, Ferracin M, Liu CG, Sabatino G, Negrini M, Maira G, Croce CM and Farace MG: Extensive modulation of a set of microRNAs in primary glioblastoma. Biochem Biophys Res Commun 334: 1351-1358, 2005.

15. He H, Jazdzewski K, Li W, Liyanarachchi S, Nagy R, Volinia S, Calin GA, Liu CG, Franssila K, Suster S, Kloos RT, Croce CM and de la Chapelle A: The role of microRNA genes in papillary thyroid carcinoma. Proc Natl Acad Sci USA 102: 19075-19080, 2005.

16. Pallante P, Visone R, Ferracin M, Ferraro A, Berlingieri MT, Troncone G, Chiappetta G, Liu CG, Santoro M, Negrini M, Croce CM, Fusco A: MicroRNA deregulation in human thyroid papillary carcinomas. Endocr Relat Cancer 13: 497-508, 2006.

17. Galardi S, Mercatelli N, Giorda E, Massalini S, Frajese GV, Ciafre SA and Farace MG: miR-221 and miR-222 expression affects the proliferation potential of human prostate carcinoma cell lines by targeting p27Kip1. J Biol Chem 282: 23716-23724, 2007.

18. Koff A: How to decrease p27Kip1 levels during tumor development. Cancer Cell 9: 75-76, 2006.

19. Fero ML, Randel E, Gurley KE, Roberts JM and Kemp CJ: The murine gene p27Kip1 is haplo-insufficient for tumour suppression. Nature 396: 177-180, 1998.

20. Ponce-Castaneda MV, Lee MH, Latres E, et al: p27Kip1: chromosomal mapping to $12 \mathrm{p} 12-12 \mathrm{p} 13.1$ and absence of mutations in human tumors. Cancer Res 55: 1211-1214, 1995.

21. Loda M, Cukor B, Tam SW, Lavin P, Fiorentino M, Draetta GF, Jessup JM and Pagano M: Increased proteasome-dependent degradation of the cyclin-dependent kinase inhibitor p27 in aggressive colorectal carcinomas. Nat Med 3: 231-234, 1997.

22. Porter PL, Malone KE, Heagerty PJ, Alexander GM, Gatti LA, Firpo EJ, Daling JR and Roberts JM: Expression of cell-cycle regulators p27Kip1 and cyclin $\mathrm{E}$, alone and in combination, correlate with survival in young breast cancer patients. Nat Med 3: 222-225, 1997.

23. Lu CD, Morita S, Ishibashi T, Hara $\mathrm{H}$, Isozaki $\mathrm{H}$ and Tanigawa $\mathrm{N}$ : Loss of $\mathrm{p} 27 \mathrm{Kip} 1$ expression independently predicts poor prognosis for patients with resectable pancreatic adenocarcinoma. Cancer 85: 1250-1260, 1999.

24. Mineta H, Miura K, Suzuki I, Takebayashi S, Amano H, Araki K, Harada H, Ichimura K, Wennerberg JP and Dictor MR: Low p27 expression correlates with poor prognosis for patients with oral tongue squamous cell carcinoma. Cancer 85: 1011-1017, 1999.

25. Migita T, Oda Y, Naito S and Tsuneyoshi M: Low expression of p27(Kip1) is associated with tumor size and poor prognosis in patients with renal cell carcinoma. Cancer 94: 973-979, 2002.

26. Chen C, Ridzon DA, Broomer AJ, Zhou Z, Lee DH, Nguyen JT, Barbisin M, Xu NL, Mahuvakar VR, Andersen MR, Lao KQ, Livak KJ and Guegler KJ: Real-time quantification of microRNAs by stem-loop RT-PCR. Nucleic Acids Res 33: e179, 2005.

27. Schmittgen TD, Jiang J, Liu Q and Yang L: A high-throughput method to monitor the expression of microRNA precursors. Nucleic Acids Res 32: e43, 2004.

28. Le Sage C, Nagel R, Egan DA, Schrier M, Mesman E, Mangiola A, Anile C, Maira G, Mercatelli N, Ciafrè SA, Farace MG and Agami $\mathrm{R}$ : Regulation of the p27(Kip1) tumor suppressor by miR-221 and miR-222 promotes cancer cell proliferation. EMBO J 26: 3699-3708, 2007.

29. Pillai RS: MicroRNA function: multiple mechanisms for a tiny RNA? RNA 11: 1753-1761, 2005.

30. Zamore PD and Haley B: Ribo-gnome: the big world of small RNAs. Science 309: 1519-1524, 2005.

31. Thomson JM, Parker J, Perou CM and Hammond SM: A custom microarray platform for analysis of microRNA gene expression. Nat Methods 1: 47-53, 2004.

32. Miska EA, Alvarez-Saavedra E, Townsend M, Yoshii A, Sestan N, Rakic P, Constantine-Paton M and Horvitz HR: Microarray analysis of microRNA expression in the developing mammalian brain. Genome Biol 5: R68, 2004.

33. Lu J, Getz G, Miska EA, Alvarez-Saavedra E, Lamb J, Peck D, Sweet-Cordero A, Ebert BL, Mak RH, Ferrando AA, Downing R, Jacks T, Horvitz HR and Golub TR: MicroRNA expression profiles classify human cancers. Nature 435: 834-838, 2005.

34. He L, Thomson JM, Hemann MT, Hernando-Monge E, Mu D, Goodson S, Powers S, Cordon-Cardo C, Lowe SW, Hannon GJ and Hammond SM: A microRNA polycistron as a potential human oncogene. Nature 435: 828-833, 2005. 
35. Felli N, Fontana L, Pelosi E, Botta R, Bonci D, Facchiano F, Liuzzi F, Lulli V, Morsilli O, Santoro S, Valtieri M, Calin GA, Liu CG, Sorrentino A, Croce CM and Peschle C: MicroRNAs 221 and 222 inhibit normal erythropoiesis and erythroleukemic cell growth via kit receptor down-modulation. Proc Natl Acad Sci USA 102: 18081-18086, 2005.

36. Poliseno L, Tuccoli A, Mariani L, Evangelista M, Citti L, Woods K, Mercatanti A, Hammond S and Rainaldi G: MicroRNAs modulate the angiogenic properties of HUVECs. Blood 108 3068-3071, 2006.

37. Kardinal C, Dangers M, Kardinal A, Koch A, Brandt DT, Tamura $\mathrm{T}$ and Welte $\mathrm{K}$ : Tyrosine phosphorylation modulates binding preference to cyclin-dependent kinases and subcellular localization of p27Kip1 in the acute promyelocytic leukemia cell line NB4. Blood 107: 1133-1140, 2006.

38. Chu I, Sun J, Arnaout A, Kahn H, Hanna W, Narod S, Sun P, Tan CK. Hengst L and Slingerland J: p27 phosphorylation by Src regulates inhibition of cyclin E-Cdk2. Cell 128: 281-294, 2007.
39. Grimmler M, Wang Y, Mund T, Cilensek Z, Keidel EM, Waddell MB, Jakel H, Kullmann M, Kriwacki RW and Hengst L: Cdk-inhibitory activity and stability of p27Kip1 are directly regulated by oncogenic tyrosine kinases. Cell 128: 269-280, 2007.

40. Hershko DD and Shapira M: Prognostic role of p27Kip1 deregulation in colorectal cancer. Cancer 107: 668-675, 2006.

41. Hengst $L$ and Reed SI: Translational control of p27Kip1 accumulation during the cell cycle. Science 271: 1861-1864, 1996.

42. Millard SS, Yan JS, Nguyen H, Pagano M, Kiyokawa H and Koff A: Enhanced ribosomal association of p27(Kip1) mRNA is a mechanism contributing to accumulation during growth arrest. J Biol Chem 272: 7093-7098, 1997.

43. Chilosi M, Chiarle R, Lestani M, Menestrina F, Montagna L, Ambrosetti A, Prolla G, Pizzolo G, Doglioni C, Piva R, Pagano M and Inghirami G: Low expression of p27 and low proliferation index do not correlate in hairy cell leukaemia. Br J Haematol 111: 263-271, 2000. 